\title{
Corrigendum
}

Genome Research 27: 677-685 (2017)

\section{Corrigendum: Discovery and genotyping of structural variation from long-read haploid genome sequence data}

John Huddleston, Mark J.P. Chaisson, Karyn Meltz Steinberg, Wes Warren, Kendra Hoekzema, David Gordon, Tina A. Graves-Lindsay, Katherine M. Munson, Zev N. Kronenberg, Laura Vives, Paul Peluso, Matthew Boitano, Chen-Shin Chin, Jonas Korlach, Richard K. Wilson, and Evan E. Eichler

Due to a formula error, Table 2 in the above article displayed incorrect values of the observed structural variants. The authors would like to correct these values and the text referring to them (page 680), which should read as follows:

Of all 461,480 insertions and deletions detected as SVs or indels, only 1.8\% of events occurred within a GENCODE or RefSeq coding exon, noncoding exon, or untranslated region (UTR) (Table 2). An additional $4.3 \%$ of events occurred in predicted noncoding regulatory regions, including DNase hypersensitivity sites, promoters $(\mathrm{H} 3 \mathrm{~K} 27 \mathrm{ac})$, and enhancers $(\mathrm{H} 3 \mathrm{~K} 4 \mathrm{me} 3)$, while $37.0 \%$ of events occurred in introns (Harrow et al. 2012).

The authors apologize for any inconvenience. Table 2 and its associated text have been updated online to reflect the corrected values.

Table 2. Summary of SVs and indels in the theoretical diploid CHM1/CHM13 by putative functional effect

\begin{tabular}{|c|c|c|c|c|c|c|c|c|}
\hline \multirow[b]{2}{*}{ Effect type $^{a}$} & \multicolumn{3}{|c|}{ Structural variants } & \multicolumn{3}{|c|}{ Indels } & \multirow[b]{2}{*}{ Total } & \multirow[b]{2}{*}{ Proportion of all events } \\
\hline & Deletion & Insertion & All & Deletion & Insertion & All & & \\
\hline Coding exon (not multiple of three) & 45 & 11 & 56 & 91 & 86 & 177 & 233 & 0.0005 \\
\hline Coding exon (multiple of three) & 57 & 84 & 141 & 223 & 214 & 437 & 578 & 0.0013 \\
\hline UTR & 49 & 67 & 116 & 2340 & 2084 & 4424 & 4540 & 0.0098 \\
\hline Noncoding exon & 116 & 121 & 237 & 1505 & 1390 & 2895 & 3132 & 0.0068 \\
\hline Noncoding regulatory ${ }^{b}$ & 542 & 869 & 1411 & 9203 & 9345 & 18,548 & 19,959 & 0.0432 \\
\hline Intronic & 4447 & 7288 & 11,735 & 85,522 & 73,613 & 159,135 & 170,870 & 0.3703 \\
\hline Functional & 5256 & 8440 & 13,696 & 98,884 & 86,732 & 185,616 & 199,312 & 0.4319 \\
\hline Not functional & 6235 & 10,061 & 16,296 & 128,866 & 117,006 & 245,872 & 262,168 & 0.5681 \\
\hline Proportion functional & 0.4574 & 0.4562 & 0.4567 & 0.4342 & 0.4257 & 0.4302 & 0.4319 & 0.4319 \\
\hline 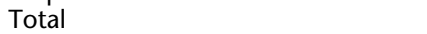 & 11,491 & 18,501 & 29,992 & 227,750 & 203,738 & 431,488 & 461,480 & 1.0000 \\
\hline
\end{tabular}

a'Annotations of coding exons, 3' and 5' UTRs, noncoding exons, and introns are based on RefSeq and GENCODE comprehensive annotations. ${ }^{\mathrm{b}}$ Regulatory regions were annotated as previously described by Gordon et al. (2016). 


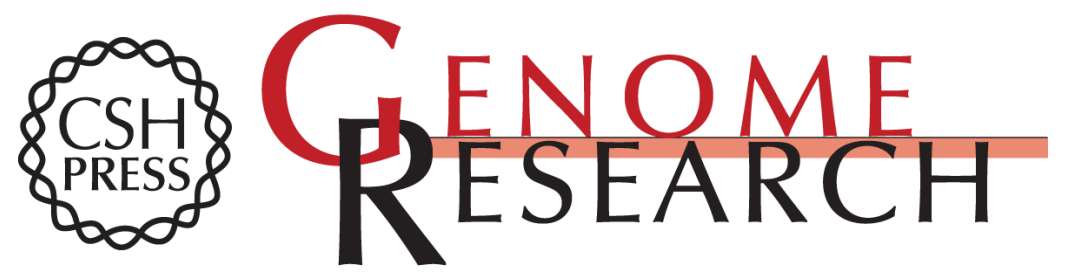

\section{Corrigendum: Discovery and genotyping of structural variation from long-read haploid genome sequence data}

John Huddleston, Mark J.P. Chaisson, Karyn Meltz Steinberg, et al.

Genome Res. 2018 28: 144

Access the most recent version at doi:10.1101/gr.233007.117

Related Content Discovery and genotyping of structural variation from long-read haploid genome sequence data

John Huddleston, Mark J.P. Chaisson, Karyn Meltz Steinberg, et al.

Genome Res. May , 2017 27: 677-685

Open Access Freely available online through the Genome Research Open Access option.

License

Email Alerting Receive free email alerts when new articles cite this article - sign up in the box at the Service top right corner of the article or click here.

\section{Affordable, Accurate Sequencing.}

To subscribe to Genome Research go to:

https://genome.cshlp.org/subscriptions 